\title{
Wie man einen Krimi schreibt
}

Erhard Taverna

erhard.taverna@saez.ch
Es sei wichtig, dass der Schreibende an seiner Geschichte selber Freude habe. Und wenn die Lust daran bis zum Ende anhalte, dann würden auch die Leser daran Gefallen finden. Mit diesen Worten begann die Krimimeisterin Patricia Highsmith ihre Anleitungen zum Verfassen einer Suspense-Story. Diese grundsätzliche Voraussetzung dürfte zweifellos für beide Autoren, Hansruedi Gehring, praktizierender Psychiater in Bern, und für Marc Gertsch, Facharzt für Innere Medizin und Kardiologie, zutreffen. Die Basis aller dramatischen Baugesetze sind die Erregung von Aufmerksamkeit und Spannung. So unterschiedlich die Romane ihre Spannungselemente konstruieren, so unterschiedlich Erzählperspektive, Tempo und Rhythmus die Handlung vorantreiben, für Überraschungen ist gesorgt. Dass der Vatikan in beiden Werken eine Rolle spielt, ist wohl ein Zufall.

\section{Der Kardinal hinkt}

Er war mit sich sehr zufrieden, heisst es am Ende der Geschichte des Polizeipräsidenten von Siena, Questore Angelo Marconi. Bis es so weit ist, braucht der Chef seinen ganzen Scharfsinn, loyale Mitarbeiter und gute Freunde. Dass der Junggeselle dabei noch zu einer schönen und gescheiten Angela kommt, mögen wir ihm gönnen. Ein Kardinal hinkt auf dem falschen Bein. Einem erfahrenen Polizeiauge kann das nicht entgehen, schon gar nicht, wenn Hochwürden einmal sein Lehrer war.

Ganz nebenbei erfährt der Leser, dass vom Archiv angeforderte Videos aus urheberrechtlichen Gründen routinemässig seitenverkehrt versandt werden, es sei denn für höhere Polizeiorgane und Gerichtsfälle. Es sind ähnliche, sachkundige Details, die mit gutgesetzten Dialogen eine aktions- und temporeiche Handlung vorantreiben. Raffiniert begründet die eingeschobene Vorgeschichte der wichtigsten Akteure eine erfolgreiche Zusammenarbeit, die eine fatale Papstwahl knapp zu verhindern weiss.

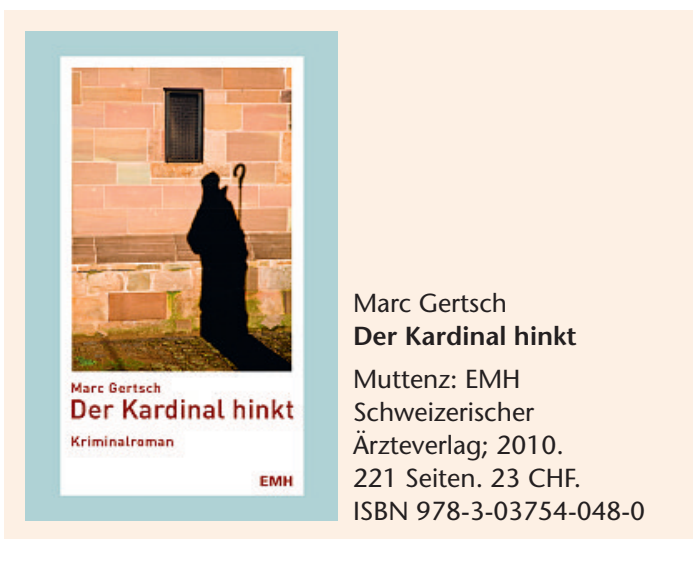

Die geschickt gesetzten Wendungen, überraschenden Schachzüge und explosiven Einschübe werden logisch und konsequent bis in die kleinsten Nebenszenen umgesetzt. Marc Gertsch hat damit gekonnt einen aussergewöhnlichen Plot, der die Mafia direkt mit dem Heiligen Stuhl verbindet, in eine spannungsvolle, unterhaltende Erzählung umgesetzt. Niemand wird in Zukunft den nächsten Rauch aus dem Vatikankamin ungerührt zur Kenntnis nehmen.

\section{Termiten an Bord}

Ein junger Mediziner besteigt in Bombay ein Passagierschiff, das eine sehr lange Reise vor sich hat. Als Sinnsuchender hat er Indien bereist, jetzt will er zurück in die Schweiz, noch ungewiss über seine berufliche Zukunft. In seiner Haltung mehr passiv als aktiv, wird er ungewollt zum Mitarbeiter des Schiffsarztes, der ihn, froh um jede Fachkraft, für die Infirmerie des ehemaligen Truppentransporters engagiert. Kaum hat der Dampfer abgelegt, stirbt der erste Notfall an einem rätselhaften Skorpionstich. Mit diesem Tod beginnt ein Reigen von gegenseitigen Verdächtigungen und klaustrophobischen Situationen in einer labyrinthischen Passagierwelt mitten auf dem Ozean. Hansruedi Gehring verknüpft geschickt das Innenleben seines Protagonisten mit den undurchsichtigen Rollenspielen eines figurenreichen Ensembles.

Wellen, Wind und ferne Ufer begleiten ein Verwirrspiel um ein geheimnisvolles Pflanzenelixier, das ein Termitenforscher mit sich führt. Eine Liebelei versüsst und kompliziert das Leben des Icherzählers, dessen Ermittlungen hoffnungslos ins Leere zu laufen drohen, bis zwei weitere Todesfälle eine unerwartete Wendung provozieren. Das «Logbuch eines Schiffsarztes», so der Untertitel des Kriminalromans, kann man auf verschiedene Weise lesen. Einfach nur als Kriminalfall mit einem überraschenden Finale oder als Initiationsgeschichte eines Indienfahrers, der nach allen Ashrams und Gurus den Meister in sich selber findet.

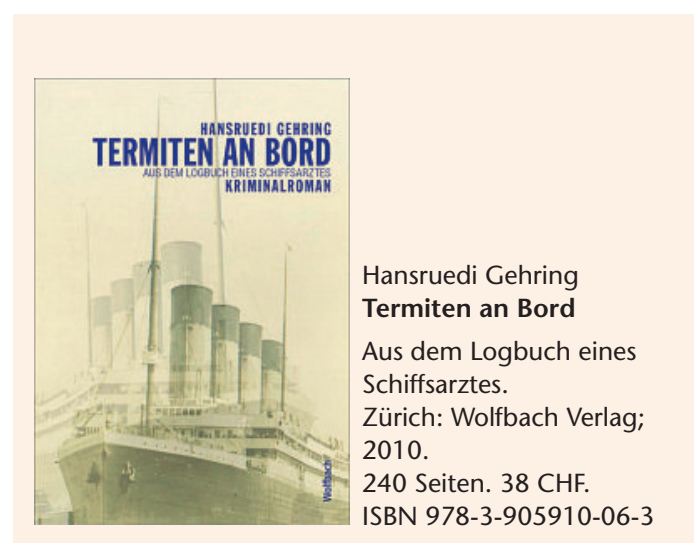

